\title{
Seroprevalence of West Nile Virus specific IgG and IgM antibodies in North-Western and Western provinces of Zambia.
}

\author{
Idah Mweene-Ndumba ${ }^{1,2}$, Seter Siziya ${ }^{3,4}$, Mwaka Monze ${ }^{2}$, Mazyanga L. Mazaba ${ }^{1,2}$, \\ Freddie Masaninga ${ }^{5}$, Peter Songolo ${ }^{5}$, Peter Mwaba $^{6}$, Olusegun A. Babaniyi ${ }^{7}$
}

1. Immunization, Vaccines and Emergencies, World Health Organization Country Office, Lusaka, Zambia

2. Pathology and Microbiology Department, University Teaching Hospital, Lusaka, Zambia

3. Clinical Sciences Department, School of Medicine, Copperbelt University, Ndola, Zambia

4. Public Health Department, University Lusaka, Lusaka, Zambia

5. Diseases Prevention and Control, World Health Organization Country Office, Lusaka, Zambia

6. Ministry of Home Affairs, Lusaka, Zambia.

7. Formerly of World Health Organization,Lusaka, Zambia.

\begin{abstract}
Background: West Nile Virus (WNV) infection has been reported worldwide, including in Africa but its existence in Zambia is unknown. Symptoms for the virus include headache, myalgia, arthralgia and rash.

Objectives: This study aimed to determine the seroprevalence of WNV and its correlates.

Methods: A cross sectional study was conducted in North-Western and Western provinces of Zambia. Samples were subjected to IgG and IgM antibodies testing against WNV. Logistic regression analyses were conducted to determine magnitudes of association.

Results: A total of 3,625 of persons participated in the survey out of which $10.3 \%$ had WNV infection. Farmers were $20 \%$ (AOR $=0.80 ; 95 \%$ CI $[0.64,0.99])$ less likely to have infection compared to students. Meanwhile participants who lived in grass roofed houses were $2.97(\mathrm{AOR}=2.97 ; 95 \% \mathrm{CI}[1.81,4.88])$ times more likely to be infected than those who lived in asbestos roofed houses. IRS was associated with reduced risk of infection (AOR $=0.81 ; 95 \%$ CI [0.69, 0.94]). Travelling to Angola was associated with the infection [AOR $=1.40 ; 95 \%$ CI [1.09, 1.81].

Conclusion: Spraying houses with insecticide residual spray would minimize mosquito-man contact. Furthermore, surveillance at the border with Angola should be enhanced in order to reduce importation of the virus into the country.

Keywords: Seroprevalence, West Wile Virus, Western province, North-Western province, Zambia

DOI: http://dx.doi.org/10.4314/ahs.v15i3.14

Cite as: Mweene-Ndumba I, Siziya S, Monze M, Mazaba ML, Masaninga F, Songolo P, Mwaba P, Babaniyi OA. Seroprevalence of West Nile Virus specific IgG and IgM antibodies in North-Western and Western provinces of Zambia. Afri Health Sci. 2015;15(3):803-9. doi: http://dx.doi.org/10.4314/abs.v15i3.14
\end{abstract}

\section{Introduction}

West Nile Virus (WNV) is a member of the flaviviridae family and genus Flavivirus, transmitted by Culex mosquito species ${ }^{1,2}$. Birds are its natural host and they play a major role in the geographic dispersion of the virus. Humans become infected by the virus through mosqui-

\author{
Corresponding author: \\ Seter Siziya, \\ Professor of Medical Biostatistics \\ The Copperbelt University \\ School of Medicine \\ Ndola Central Hospital, 6th Floor \\ P.O. Box 71191 \\ Ndola, Zambia \\ Tel: 260-212-618511 \\ Cell: +260955 752646 \\ Email: ssiziya@gmail.com
}

to bites ${ }^{3-5}$. It is estimated that one out of 150 human infections could result in severe neurologic symptoms with a death rate of $10 \%$ among severe cases ${ }^{6-8}$. Most of the infections are usually asymptomatic but those who show symptoms come down with headaches, myalgia, arthralgia and rash. Currently no treatment exists for arboviral diseases and there are no licensed vaccines for humans, therefore preventive measures against infection with WNV are encouraged ${ }^{9-11}$.

The virus was first discovered in Uganda in $1937^{12}$. In America, the disease was not considered as an important health problem until 1999 when 62 deaths occurred in North America ${ }^{13,14}$. The disease has since been reported globally ${ }^{15}$. Several WNV seroprevalence studies had been conducted worldwide including; Italy, the United States of America and Romania. In Italy WNV seroprevalence ranged from 3 per 1,000 blood donors to 33 per 1,000 blood donors ${ }^{16}$. Studies in USA 
indicated that in-country variations existed with higher WNV seroprevalence rates in the Western and central areas (19.7\% and $13.8 \%$ respectively) and lower rates of $4.2 \%$ in the Eastern parts ${ }^{17}$.

WNV human infections had been reported in many African countries. Studies conducted in Egypt in the 1950s and 1970s showed WNV antibodies in serum samples of more than $60 \%$ of the study population and $74 \%$ in Upper parts of Egypt and 28\% around Cairo ${ }^{18}$. In Tunisia, in the 1960s and some areas in North Africa showed a seroprevalence of $5 \%$, while Senegal reported higher rates of up to $98 \% \%^{2}$. Prevalence rates of 3-65\% were reported in Kenya between 1966 and $1968^{2}$ and $9.2 \%$ in $2011^{19}$. Studies in South Africa reported seroprevalence of 13-24\% in 1961-1965 PubMed and up to $45 \%$ in Madagascar ${ }^{2}$.

Several risk factors for WNV infection emerged from the study in America such as climate and transmission even after adjusting for other environmental factors ${ }^{20}$ and the results were comparable to results obtained in other studies which confirmed an association between urban/sub-urban versus a more rural area ${ }^{21,22}$. However other studies reported significant association when there was less population density and rural. Temperature changes determining human activity and mosquito replication was also significantly associated with risk of infection. It was also concluded that these factors could differ yearly due to changes in bird populations with high bird population as being protective ${ }^{20}$. It is possible that when there are more birds the virus could be concentrated in bird mosquito bird cycle whereas if there are fewer birds the mosquito could resort to human meals. In Arizona staying at home and not attending school was found to be a risk factor to WNV infection, although it was argued that the possibility that those who stayed at home were the elderly who were already known to be at high risk of infection with $\mathrm{WNV}^{11}$. Seroprevalence studies conducted in Cameroon had indicated that iron roofed houses were protective for the infection compared to grass thatched houses ${ }^{23}$.

Studies had also confirmed that age had a bearing on the severity of the infection with the older age group, 50 years and above, being most at risk ${ }^{20}$. However other studies reported that WNV affects all age groups; In Israel and other parts of Africa infection was reported in children and healthy adults ${ }^{2,24}$. In Kenya the seroprevalence tended to increase with age ${ }^{19}$.

Although WNV infection has been reported worldwide, there has been no information on the extent of the problem in Zambia. Therefore, this study was conducted to determine the seroprevalence of WNV IgG and IgM antibodies and its correlates in Zambia during a Yellow fever risk assessment survey.

\section{Methods}

\section{Study site, design and population}

The study was conducted in North-Western and Western provinces of Zambia. The selection of the two provinces was based on the classification as low potential risk areas for yellow fever transmission by World Health Organization (WHO) in 201025. North-Western province which borders with Angola on the western side and Democratic Republic of Congo (DRC) on the northern side has a population of $706,462^{26}$. It is the most sparsely populated province in the country and the provincial capital is Solwezi. The province comprised of 8 districts which were divided into 1178 Standard Enumeration Aras (SEAs) and the main economic activities were mining in one district and general pineapple growing. Western province with a population of 881,524, borders with Angola and has seven districts (Census 2010) divided into 1902 SEAs. The main economic activities were crop farming, livestock production and fishing. A cross sectional study was carried out among individuals aged nine months or older.

\section{Sample size, inclusion/exclusion criteria and sam- pling}

The sample size calculation was based on the assumption that the sero-prevalence was $7 \%$ based on the study conducted by Robinson ${ }^{27}$. In estimating the sample size for persons aged 5 years or older, the following parameters were considered: a prevalence of $7 \%$, desired precision or confidence interval (d) of $+3 \%$, and a design effect (DE) of 2 and an 80\% response rate. Considering sex, we aimed to recruit 700 male and 700 female participants in each province. Assuming an average of 4 persons aged 5 years or older in each household, a total of 12 households in each of the 30 cluster was to be recruited in the survey. The total number of persons that would be recruited from each province was 1806, totaling 3612 from both provinces. 
The seroprevalence of children was about half that for older children, and in estimating the sample size for persons aged below 5 years, the following parameters were considered: a prevalence of $3.5 \%$, desired precision or confidence interval (d) of $+3.4 \%$, and a design effect (DE) of 2 and an 80\% response rate. The computed sample size was 282 . Therefore, in each province 406 children would be recruited for the survey.

Included in the study were individuals aged 9 months or older who were found in a sampled household at the time of the study and were resident in the study site for at least seven days. Individuals who had received YF vaccination in the last ten years to the survey were also included in the survey. Excluded from the study were persons who were aged less than 9 months, or individuals regardless of age who resided in the study site for less than 7 days prior to the survey. Children under the age of 9 months were excluded based on the fact that at this age children could still carry maternal antibodies from exposed mothers which could pose the risk of false positive results.

The sample was drawn using a two-stage cluster sampling technique using probability proportional to size. A list of the standard enumeration areas (SEAs) in each province constituted the sampling frame. The line lists of the SEAs were provided by the Government's Central Statistics Office (CSO). The sampling was designed to achieve fairly good estimates at the provincial level of analysis, and not representing the sub divisions of the province.

\section{Study Variables}

Dependent variable: A case with evidence of WNV exposure was defined as any individual aged 9 months or older whose blood sample was confirmed to have WNV exposure. WNV exposure status was positive if $\mathrm{IgG}$ or IgM antibodies were determined in the serum sample by laboratory testing and negative if the $\mathrm{IgG}$ or IgM antibodies were absent by laboratory testing.

Independent variables: The independent variables included demographic data: age, sex, occupation, education, roof type and use of mosquito preventive measures such as insecticide treated nets (ITNs) and indoor residual spray (IRS).

\section{Laboratory procedures}

Three to 5 millilitres of blood was collected by ve- nepuncture into an EDTA vaccutainer tube and transported on cold chain to the local laboratories for serum separation and storage.

Subsequently serum samples were transported on cold chain and thereafter subjected to primary testing (YFV specific $\operatorname{IgG}$ and $\operatorname{IgM}$ ) at the University of Teaching Hospital in Zambia virology unit and Institute Pasteur, Dakar. All presumptive YFV-specific IgG and IgM samples were subjected to IgG and IgM antibodies testing against other flaviviruses known to cause haemorrhagic fever-likedisease including WNV. The testing was carried out using IgG capture enzyme-linked immunosorbent assay (ELISA).

\section{Data management and analysis}

Data collected from the field was entered in an Epi-Info data entry screen that had consistency and range checks embedded in it. Further editing was conducted by running frequencies during the analysis stage. Epi data files were exported to SPSS for data analysis. The data was summarized to describe the occurrence of WNV exposed individuals in absolute numbers and percentage by place (residence, travel or work) and person (age, sex, occupation, education). Further analysis was conducted to determine independent factors associated with WNV sero-positivity. Odds ratios were used to estimate the magnitude of associations.

\section{Ethical considerations}

Ethical clearance was sought from the Tropical Diseases Research Centre Research Ethics Committee, and ethical standards were adhered to throughout this study. Informed consent was sought from study participants. Guardians provided assent for the participation of the persons under the consenting age. They were asked to read or have read to them, understand and sign/thumbprint an informed consent form. Responsible adults in the household were identified to give proxy consent on behalf of minors.

\section{Results}

Table 1 provides a description of the respondents in the two provinces. A total of 3,625 persons participated in the survey. About 1 in 5 of the participants was in the age groups $5-14$ years $(23.9 \%)$ and $15-24$ years $(20.6 \%)$. The sample comprised more female participants $(53.3 \%)$. Male participants tended to be more educated than females $(\mathrm{p}<0.001)$ with $35.9 \%$ of male and $26.6 \%$ of female participants having attained secondary level of education or higher. 
Table 1: Sample description for the two provinces

\begin{tabular}{|c|c|c|c|c|c|c|}
\hline Factors & Total & $\%$ & Male & $\%$ & Female & $\%$ \\
\hline \multicolumn{7}{|c|}{ Age $($ years $)[x 2=10.41, p=0.065]$} \\
\hline$<5$ & 335 & 9.4 & 155 & 9.3 & 178 & 9.4 \\
\hline $5-14$ & 853 & 23.9 & 424 & 25.4 & 429 & 22.6 \\
\hline $15-24$ & 738 & 20.6 & 344 & 20.6 & 392 & 20.6 \\
\hline $25-34$ & 593 & 16.6 & 245 & 14.7 & 348 & 18.3 \\
\hline $25-44$ & 460 & 12.9 & 214 & 12.8 & 245 & 12.9 \\
\hline $45+$ & 596 & 16.7 & 286 & 17.1 & 310 & 16.3 \\
\hline \multicolumn{7}{|l|}{ Sex } \\
\hline Male & 1669 & 46.7 & & & & \\
\hline Female & 1902 & 53.3 & & & & \\
\hline \multicolumn{7}{|c|}{ Education $[x 2=41.72, p<0.001]$} \\
\hline None & 758 & 21.5 & 312 & 19.0 & 444 & 23.6 \\
\hline Primary & 1680 & 47.6 & 741 & 45.1 & 937 & 49.8 \\
\hline Secondary & 996 & 28.2 & 529 & 32.2 & 466 & 24.8 \\
\hline $\begin{array}{l}\text { College } \\
\text { University }\end{array}$ & 95 & 2.7 & 61 & 3.7 & 34 & 1.8 \\
\hline \multicolumn{7}{|c|}{ Occupation $[\times 2=245.60, p<0.001]$} \\
\hline $\begin{array}{l}\text { House } \\
\text { wife/husband }\end{array}$ & 307 & 8.7 & 18 & 1.1 & 289 & 15.4 \\
\hline Farming & 1233 & 35.1 & 573 & 35.1 & 659 & \\
\hline
\end{tabular}

No significant association was observed between West Nile virus infection and $\operatorname{sex}(\mathrm{p}=0.868)$. Overall, $10.3 \%$ of the participants had WNV infection.

Table 2 provides an analysis of factors associated with West Nile Virus infection. Of the factors considered, age, education, occupation, roof type, sleeping under an ITN, house with IRS, visited DRC, visited Angola, occupation and roof type were significantly associated with West Nile infection. Compared with participants of age 45 years or older, participants aged less than 5 years were $62 \%(\mathrm{AOR}=0.38$; 95\% CI [0.20, 0.73]) less likely to have infection, while, participants aged 35-44 years were $41 \%(\mathrm{AOR}=1.41$; 95\% CI [1.01-1.97]) more likely to have infection.

Table 2: Factors associated with West Nile Virus infection in bivariate and multivariate analysis for two provinces

\begin{tabular}{|c|c|c|c|c|}
\hline Factor & OR & $95 \% C I$ & AOR & $95 \% C I$ \\
\hline \multicolumn{5}{|l|}{ Age (years) } \\
\hline$<5$ & 0.31 & (0.18-0.53) & 0.38 & $(0.20-0.73)$ \\
\hline $5-14$ & 0.73 & $(0.56-0.94)$ & 0.73 & $(0.50-1.08)$ \\
\hline $15-24$ & 1.06 & $(0.83-1.36)$ & 1.07 & $(0.82-1.42)$ \\
\hline $25-34$ & 1.18 & $(0.91-1.53)$ & 1.06 & $(0.77-1.48)$ \\
\hline $35-44$ & 1.49 & (1.14-1.94) & 1.41 & $(1.01-1.97)$ \\
\hline $45+$ & 1 & & 1 & 1 \\
\hline \multicolumn{5}{|l|}{ Sex } \\
\hline Male & 1.02 & $(0.91-1.13)$ & - & \\
\hline Female & 1 & & & \\
\hline \multicolumn{5}{|l|}{ Education } \\
\hline None & 0.86 & $(0.65-1.14)$ & 0.83 & $(0.60-1.15)$ \\
\hline Primary & 1.42 & $(1.12-1.80)$ & 1.32 & $(1.01-1.72)$ \\
\hline Secondary & 1.04 & $(0.80-1.35)$ & 0.98 & $(0.74-1.30)$ \\
\hline College/University & 1 & & 1 & \\
\hline \multicolumn{5}{|c|}{ Slept under mosquito net } \\
\hline Yes & 1.13 & $(1.01-1.27)$ & 1.13 & $(1.00-1.27)$ \\
\hline No & 1 & & 1 & \\
\hline \multicolumn{5}{|l|}{ House with IRS } \\
\hline Yes & 0.83 & $(0.72-0.96)$ & 0.81 & $(0.69-0.95)$ \\
\hline No & 1 & & 1 & \\
\hline \multicolumn{5}{|c|}{ Travelled to Congo DR } \\
\hline Yes & 0.30 & $(0.11-0.79)$ & 0.28 & $(0.10-0.74)$ \\
\hline No & 1 & & 1 & \\
\hline \multicolumn{5}{|l|}{ Travelled to Angola } \\
\hline Yes & 1.68 & $(1.32-2.12)$ & 1.40 & $(1.09-1.81)$ \\
\hline No & 1 & & 1 & \\
\hline
\end{tabular}


Participants who had attained primary level of education were $32 \%$ (AOR $=1.32$; 95\% CI $[1.01,1.72])$ more likely to have infection compared to participants who had attained higher level of education. Farmers were $20 \%(\mathrm{AOR}=0.80 ; 95 \%$ CI $[0.64,0.99])$ less likely to have infection compared to students. Meanwhile, participants who lived in grass roofed houses were 2.97 $(\mathrm{AOR}=2.97 ; 95 \% \mathrm{CI}[1.81,4.88])$ times more likely to be infected than those who lived in asbestos roofed houses. Compared with participants who did not have their houses sprayed those who had IRS in their houses were $19 \%$ (AOR $=0.81 ; 95 \%$ CI $[0.69,0.94])$ less likely to have infection. Participants who had travelled to DRC were $72 \%(\mathrm{AOR}=0.28 ;(\% \%$ CI $[0.10,0.74])$ less likely to have infection compared with those who did not travel there. Travelling to Angola was associated with the infection $[\mathrm{AOR}=1.40 ; 95 \% \mathrm{CI}[1.09,1.81])$.

\section{Discussion}

This study presents the first documentation of the seroprevalence of WNV infection and its correlates in Zambia. The results of this survey revealed a seroprevalence of $10.2 \%$. The following factors were statistically significantly associated with the infection: age, education, occupation, roof type, living in a house with IRS, sleeping under a mosquito net and visiting Congo DR and Angola.

The seroprevalence results obtained in this study were consistent with results from surveys conducted in other parts of the world including Africa although in some areas very high seroprevalence rates of WNV infection were obtained. The seroprevalence in USA varied across the country with rates ranging from $4.2 \%-19.7 \%{ }^{19}$. In Africa higher rates of (60\%-74\%) in Egypt, (3\%-65\%) in Kenya and (13\%-24\%) in South Africa, were reported as way back as the 1950 s to $1970 \mathrm{~s}^{2,17}$. It is also important to note that most of these studies were conducted on blood donors following an outbreak, which could explain the marked difference in the rates obtained in this study.

Disease prevalence is dependent upon a wide range of risk factors, climate and the environment affecting the activities of the virus and the humans ${ }^{20-22,28}$. This study has shown that being younger than 5 years old was protective to the WNV infection while literature indicates that all age groups are at risk for the disease ${ }^{20}$. This study however indicates that those aged between 35-44 years of age were more likely to acquire the infection compared to those who were 45 years older. Contrary to other literature which suggests that those above 50 years of age were more at risk for the disease compared to those below the age of 50 years $^{20}$.

Regarding vector management and control the study has shown that participants, who had a house with IRS, were less likely to be infected with the virus compared to those who did not have their houses sprayed. Therefore the national malaria control program should sustain efforts to attain higher IRS coverage as this provides protection again arthropod-borne viruses, including the WNV, in addition to malaria, to the beneficiaries. CDC guidelines on WNV surveillance control and prevention call for active surveillance of the disease in humans and integrated vector management. The guidelines emphasize that since WNV outbreaks are non-predictable there is a need for active surveillance to monitor and detect increases in the disease rates and to have control measures readily available for outbreak response.

There is evidence of arboviral outbreaks in Africa with recent reports of dengue outbreaks in Angola, DRC and Tanzania, which are neighbors with Zambia. Travel between Zambia and these countries is inevitable, increasing the risk of viral importation. This study provides evidence that participants who had a history of travelling to Angola were at an increased risk of being infected with WNV. Human movement has been implicated in the spread and transmission of vector borne diseases including $\mathrm{WNV}^{29}$. It should therefore be emphasized that travelers take personal protective measures against mosquito bites as a preventive measure.

Concerning education level of the participants, this study demonstrates that compared to participants who had attained tertiary level of education, those who had attained primary school level of education were more likely to be infected with WNV. This finding contradicts studies in Arizona which indicated that those who did not attend school were more at risk of the disease than those who attended school ${ }^{11}$. This is not surprising as literacy is generally a symbol of improved socioeconomic status leading to increased chances of access to medical care resulting in reduced chances of exposure to the disease ${ }^{29}$. 
This study has indicated that seropositivity was significantly associated with living in grass thatched houses compared to living in asbestos roofed houses. Contrary to results in Cameroon where grass thatched houses were protective against vector borne diseases compared to the iron roofed houses ${ }^{23}$. Regarding occupation of the participants, being a farmer was protective to the infection. This finding suggests that mosquito-man contact may not be occurring when farmers are in the field.

The findings in this study could be limited by the fact that the results were based on primary $\operatorname{Ig} G$ and $\operatorname{IgM}$ antibody test. Plaque Reduction Neutralization Test (PRNT) was not done. This could have inflated the seropositivity for WNV since the cross reactivity of arboviruses was not taken into consideration, although another similar study which carried out the PRNT following the primary test showed that about $80 \%$ of the primary results were confirmed ${ }^{1}$. The other limitation could be the fact that the association of WNV and the veterinary and avian populations which exist in the provinces was not done.

\section{Conclusion}

This study provides evidence that WNV infection is prevalent in North-Western and Western provinces of Zambia. Further studies are needed to determine the disease burden in veterinary, mosquitoes, avian and humans. Spraying houses with insecticide residual spray would minimize mosquito-man contact. Furthermore, surveillance at the border with Angola should be enhanced in order to reduce importation of the virus into the country.

\section{Acknowledgements}

We are grateful to the interviewers for their dedicated work to successfully complete the survey. The survey could not have been successful without the cooperation of the participants and the virology laboratory staff (Hope Nkamba, Julia Chibumbya and Cynthia Phiri-Mubanga), for testing of the samples. The survey was funded by the Ministry of Health [Zambia] and the World Health Organization.

\section{References}

1. Pezzotti P, Piovesan C, Barzon L, et al. Prevalence of IgM and IgG antibodies to West Nile virus among blood donors in an affected area of north-eastern Italy, summer 2009. Euro Surveill 2011; 16(10).
2. Murgue B, Murri S, Triki H, Deubel V, Zeller HG. West Nile in the Mediterranean basin: 1950-2000. Ann N Y Acad Sci 2001; 951: 117-126 PubMed.

3. Weaver SC, Reisen WK. Present and future arboviral threats. Antiviral Res 2010; 85(2): 328 PubMed -345.

4. Komar N, Langevin S, Hinten S, et al. Experimental infection of North American birds with the New York 1999 strain of West Nile virus. Emerg Infect Dis 2003; 9(3): 311 PubMed -322.

5. Malkinson M, Banet C. The role of birds in the ecology of West Nile virus in Europe and Africa. Curr Top Microbiol Immunol 2002; 267: 309-322.

6. Petersen LR, Marfin AA. West Nile virus: a primer for the clinician. Ann Intern Med 2002; 137(3): $173 \mathrm{Pu}-$ bMed -179 .

7. Sejvar JJ, Haddad MB, Tierney BC, et al. Neurologic manifestations and outcome of West Nile virus infection JAMA. 2003; 290(4): 511-515.

8. O'Leary DR, Marfin AA, Montgomery SP, et al. The epidemic of West Nile virus in the United States, 2002. Vector Borne Zoonotic Dis 2004; 4(1): 61-70.

9. Chang GJ, Kuno G, Purdy DE, Davis BS. Recent advancement in flavivirus vaccine development. Expert Rev Vaccines 2004; 3(2): 199-220.

10. LaBeaud AD, Kile JR, Kippes C, King CH, Mandalakas AM. Exposure to West Nile virus during the 2002 epidemic in Cuyahoga County, Ohio: a comparison of pediatric and adult behaviors. Public Health Rep 2007; 122(3): 356 PubMed -361.

11. Gibney KB, Colborn J, Baty S, et al. Modifiable risk factors for West Nile virus infection during an outbreak--Arizona, 2010. Am J Trop Med Hyg 2012; 86(5): 895 PubMed -901.

12. Smithburn KC, Hughes TP, Burke AW, Paul JH. Aneurotropic virus isolated from the blood of a native of Uganda. Am J Trop Med 1940; 20: 471-472 PubMed .

13. Gubler DJ. The continuing spread of West Nile virus in the western hemisphere. Clin Infect Dis 2007; 45(8): 1039 PubMed -1046.

14. Nash D, Mostashari F, Fine A, et al. The outbreak of West Nile virus infection in the New York City area in 1999. N Engl J Med 2001; 344(24): 1807 PubMed -1814. 15. Petersen LR, Carson PJ, Biggerstaff BJ, Custer B, Borchardt SM, Busch MP. Estimated cumulative incidence of West Nile virus infection in US adults, 19992010. Epidemiol Infect 2013; 141(3): 591 PubMed -595.

16. Barzon L, Pacenti M, Cusinato R, et al. Human cases of West Nile Virus Infection in north-eastern Italy, 15 June to 15 November 2010. Euro Surveill. 2011;16(33):pii=19949. 
17. Schweitzer BK, Kramer WL, Sambol AR, Meza JL, Hinrichs SH, Iwen PC. Geographic factors contributing to a high seroprevalence of West Nile virus-specific antibodies in humans following an epidemic. Clin Vaccine Immunol 2006; 13(3): 314-318.

18. Darwish MA, Ibrahim AH. Survey for antibodies to arboviruses in Egyptian sera. I. West Nile virus antihemagglutinins in human and animal sera. $J$ Egypt Public Health Assoc 1971; 46(2): 61-70.

19. Mease LE, Coldren RL, Musila LA, et al. Seroprevalence and distribution of arboviral infections among rural Kenyan adults: a cross-sectional study. Virol J. 2011; 8: 371 .

20. Liu A, Lee V, Galusha D, et al. Risk factors for human infection with West Nile Virus in Connecticut: a multi-year analysis. Int J Health Geogr 2009; 8: 67.

21. Brown HE, Childs JE, Diuk-Wasser MA, Fish D. Ecological factors associated with West Nile virus transmission, northeastern United States. Emerg Infect Dis 2008; 14(10): 1539 PubMed -1545.

22. Gibbs SE, Wimberly MC, Madden M, Masour J, Yabsley MJ, Stallknecht DE. Factors affecting the geographic distribution of West Nile virus in Georgia, USA: 2002-2004. Vector Borne Zoonotic Dis 2006; 6(1): 73-82.

23. Kuniholm MH, Wolfe ND, Huang CY, et al. Sero- prevalence and distribution of Flaviviridae, Togaviridae, and Bunyaviridae arboviral infections in rural Cameroonian adults. Am J Trop Med Hyg 2006; 74(6): 1078 PubMed -1083.

24. Zeller HG, Schuffenecker I. et al. West Nile virus: an overview of its spread in Europe and the Mediterranean basin in contrast to its spread in the Americas. Eur J Clin Microbiol Infect Dis 2004; 23(3): 147-156.

25. Jentes ES, Poumerol G, Gershman MD, et al. The revised global yellow fever risk map and recommendations for vaccination, 2010: consensus of the Informal WHO Working Group on Geographic Risk for Yellow Fever. Lancet Infect Dis 2011; 11(8): 622 PubMed -632.

26. Central Statistical Office. 2010 census of population and housing. National analytical report. Lusaka: CSO, 2012.

27. Robinson GG. A note on mosquitoes and yellow fever in Northern Rhodesia. East Afr Med J 1950; 27(7): 284 PubMed -288.

28. Paz S, Semenza JC. Environmental drivers of West Nile fever epidemiology in Europe and Western Asia--a review. Int J Environ Res Public Health 2013; 10(8): 35433562.

29. Stoddard ST, Morrison AC, Vazquez-Prokopec GM, et al. The role of human movement in the transmission of vector-borne pathogens. PLoS Negl Trop Dis 2009; 3(7): PubMed e481. 